\title{
PHYSICAL-MECHANICAL PROPERTIES AND DURABILITY OF HYDRAULIC LIME-BASED MORTARS WITH NON-TRADITIONAL BIOPOLYMERS
}

\author{
Tomáš ŽižlavskÝ*, Martin Vyšvařil, Pavla RovnaníKová \\ Brno University of Technology, Faculty of Civil Engineering, Veveři 331/95, 602 00 Brno, Czech Republic \\ * corresponding author: zizlavsky.t@fce.vutbr.cz
}

\begin{abstract}
The study focuses on the influence of addition of four different biopolymers in various doses $(0.1 \%, 0.5 \%$, and $1 \%)$ on the physical-mechanical properties and durability of NHL 3.5 mortars prepared with constant water/binder ratio and the binder/aggregate ratio of $1: 2$ by weight. The flow table test was carried out and the specimens were tested for flexural and compressive strength at the age of 7 and 28 days. The durability coefficient for the flexural strength was calculated after 15 freezing-thawing cycles. All the admixtures have dosage-dependent slump reducing effect. The strengths were increased in comparison with mortar with no admixture, the most significantly in the case of highest dose of carrageenan and diutan gum. All biopolymers with the exception of diutan gum increased the durability coefficient with increasing dosage. Sodium salt of alginic acid has been found the most effective in the case of durability improvement.
\end{abstract}

KEYwORDS: Natural hydraulic lime, sodium alginate, carrageenan, diutan gum, xanthan gum, compressive strength, flexural strength, durability.

\section{INTRODUCTION}

Hydraulic lime has been, as the strongest and most versatile binder, used since the ancient times. Natural hydraulic lime is prepared by burning limestone with clay impurities on similar temperatures as a pure limestone. During the burning process the clay decomposes creating silicate and aluminate phases in the binder, which reacts with calcium hydroxide creating minerals similar to clinker minerals in cement. The hydraulic lime hardens firstly by hydraulic reactions and afterwards by carbonation of the rest of the $\mathrm{Ca}(\mathrm{OH})_{2}$.

Viscosity enhancing admixtures (VEAs) are lately widely studied for the use in concrete to improve properties especially of self-consolidating concrete. Their use in lime mortars is far less studied, partially due to the amount of production of concrete in comparison with lime for the building purposes. VEAs are supposed to improve plasticity of the mortars, their fresh state adhesion, and to eliminate the sagging of renders, mostly by their water-retaining function. [1, 2]

The previous results declare, that even though most of the VEAs are polysaccharides, due to the amount needed to improve concrete properties they do not slow the hydratation reactions of clinker minerals in cement, therefore, if the dosage is similar, they should not affect the hydratation reaction of NHL mortar neither. [1, 3]

The current study focuses on the impact of addition of non-traditional biopolymerical VEAs on the hardened properties and durability of natural hydraulic lime-based mortar. The biopolymers used are microbial based (xanthan gum (XG), and diutan gum (DG)) and seaweed based (carrageenan (CG), and sodium salt of alginic acid (ALGNA)). All of these biopolymers are currently used in food industry as gelling and thickening agents, and stabilisers $4-6$. The most well-known in the building industry are the XG and DG, which are partially in use in self consolidating concrete to reduce segregation and bleeding [4, 5, 7]. DG is more flexible in the use in comparison with XG for its properties are independent on mono- and bi-valent (e.g. $\mathrm{Ca}^{2+}$ ) cations concentration as well as the temperature [7-12]. The cationic sensitivity lead to significantly different behaviour of these two biopolymers in lime mortars, where DG improved the strength characteristics and XG notably reduce them, especially the compressive one [13]. The XG was chosen for the research on the hydraulic lime properties, even though it didn't performed well, mainly because it is reported to have positive influence on concrete behaviour, and the NHL solution contains much less $\mathrm{Ca}^{2+}$ cations than the lime putty. Sodium and calcium salts of alginic acid have surpassed the commercial super absorbent polymers especially in the way of influence on the hydratation of cementbased mortars and their addition suppressed the same problems as DG and XG addition [8, 14. In the aerial lime-based mortar 13 ALGNA was one of the best performing admixtures, even though its initial strength reduction with growing dose caused by the highest humidity of the specimens. The use of CG has been reported mainly in geopolymers, for the fly-ash based one its addition increased strengths by creating more condensed structure. [15] This result was lately supported by Z. Abdollahnejad et al. [16] in the study on alkali activated cement based binder 
mortars with fly-ash and waste glass addition, where CG addition lead to better workability and also to higher compressive strength, while adding the XG had no positive effect on the strength properties. In the lime mortar CG for the initial strength characteristics didn't performed well, but showed interesting hint of improvement for the long-term properties. 13

\section{MATERIALS AND METHODS}

\subsection{MATERIALS}

For the preparation of mortar samples same materials as for the previous work [13] were used: the NHL 3.5 lime according to EN 459-1 has been mixed with the siliceous sand fraction 0-4 mm (Českomoravský štěrk a.s., Hulín, Czech republic) in a 1:1 volumetric ratio. Then the biopolymer was added in the dose of $0.1 \%$, $0.5 \%$ and $1 \%$ of the weight of binder. The admixtures used were products of Sigma-Aldrich co (ALGNA) and CP Kelco (Kelco-crete DG-F - DG, Genuvisco CG-131 - CG, and Kelzan AP-AS - XG). The dry mixture was introduced into water of constant water : binder ratio of 0.7 . The flow value was determined according to EN 1015-3. The samples were then cast into $40 \times$ $40 \times 160 \mathrm{~mm}$ prismatic moulds, and demoulded after 48 hours. The beams were stored in the laboratory conditions $\left(20^{\circ} \mathrm{C}, 50 \%\right.$ relative humidity) until the day of testing.

\subsection{Methods}

The methodology of the experiments is similar to the previously published results [13]: bulk density of the mortar was determined by weighting and measuring the samples before the strength tests, flexural and compressive strength tests were carried out according to EN 1015-11 at 7 and 28 days of age of the mortars. After 28 days of curing time in the laboratory conditions samples underwent the freezing-thawing durability test for 15 cycles according to CSN 72 2452. The reference samples were stored under water to simulate similar conditions as the tested samples. The durability coefficient for flexural strength after 15 cycles has been determined.

\section{Results AND Discussion}

\subsection{Flow VAlues}

Addition of any of the admixtures caused workability reduction varying on the dosage and type of the admixture. The results are presented in the figure 1 We can see, that the highest flow value reduction is, as well as for the lime mortar, in the case of DG [13]. The trends are similar to aerial lime-based mortar with exception of XG where the difference is more significant due to the earlier-stated concentration of $\mathrm{Ca}^{2+}$ cations in the solution [7, 9, 12].

\subsection{BULK DENSITY OF MORTAR}

In the figure 1 there can be seen a decreasing trend in bulk density of the mortar. This is in this case caused by air entrained due to different workability of the mortars, for all of the specimens consisted of the same water : binder : aggregate ratio, the trend corresponds with the flow value reduction one and as has been stated earlier these biopolymers did not show air-entraining function 13 .

\subsection{FleXURAL AND COMPRESSIVE STRENGTH}

The results obtained by strength tests are presented in figures 2 and 3 . The 7 days strength was far less affected, than in the case of lime mortars with different biopolymers [13, 17, 18, but even less affected than the expectations based on the results obtained on cement or NHL mortars found in the literature [14, 19, 20. All the biopolymers and doses with exception of lowest dosage $(0.1 \%)$ of polymers for flexural strength surpassed the strength of mortar with none of the biopolymers. For the flexural strength the DG and CG in highest dosage (1\%) exceeded significantly all other biopolymers confirming the earlier results on lime mortar [13 and the presumption based on literature research [15, 16]. The XG performed much better then while used in aerial lime-based mortar, but in comparison with other biopolymers, the 28 days results were one of the worst ones. The overall increase of strengths in this experimental set up may be as well interpreted as the impact of dewatering, which can be partially described by the flow value reduction, but the dewatering effect may not cause so enormous difference in strength as in the case of CG and DG [21].

\subsection{Durability}

The results of durability tests carried out after 15 freezing-thawing cycles were summarized in table 1 The durability coefficient for flexural strength was chosen, for it is more representative if the material is used as a plaster. Most of the specimens tested survived 15 freezing thawing cycles in the way, they could be tested for flexural and compressive strength. The most damaged were beams prepared from mortar with DG addition of $0.1 \%$ and $0.5 \%$ (fig. 4) out of the three beams for each mixture only one was compact enough for the three point bending test and even though the test results indicated several damage to the specimens, thus the durability coefficient of DG 1 and DG 5 mortars should be approached with a distance. Overall the biopolymer addition lead to improvement of durability as expected based on results found in the literature [3, 17, 18, 22, 23. The DG addition notably worsens the durability, so it's even lower than the one of mortar with no admixture. With the growing dosage of biopolymeric admixture the mortar became more durable. The best performing were ALGNA and $\mathrm{XG}$, which even in the lowest dose $(0.1 \%)$, improved the durability significantly. According to ČSN 722452 

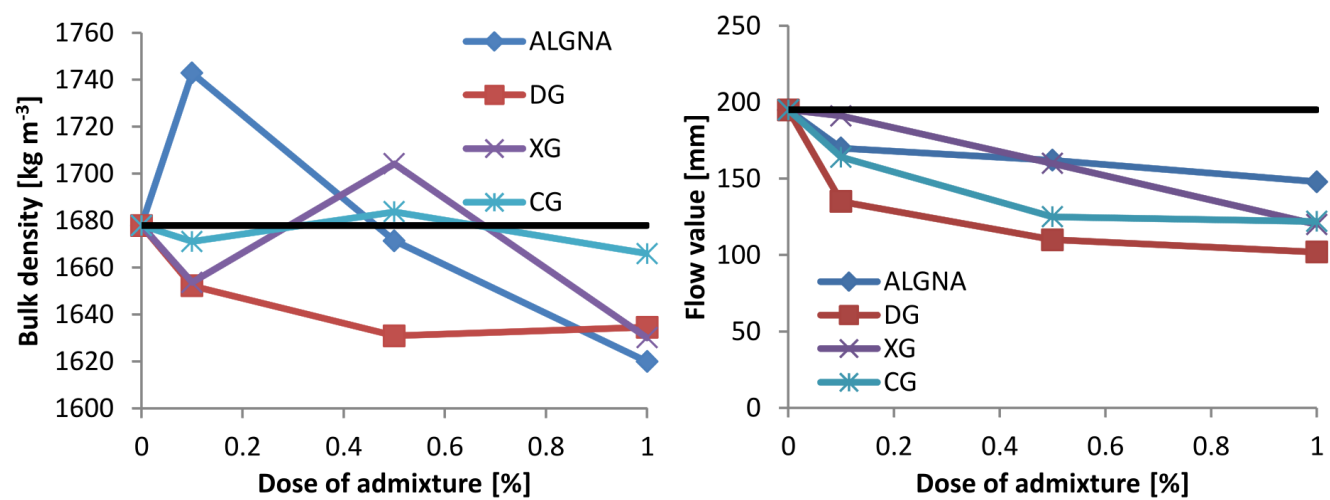

Figure 1. Flow values of fresh mortars and bulk density of 7 days old specimens.
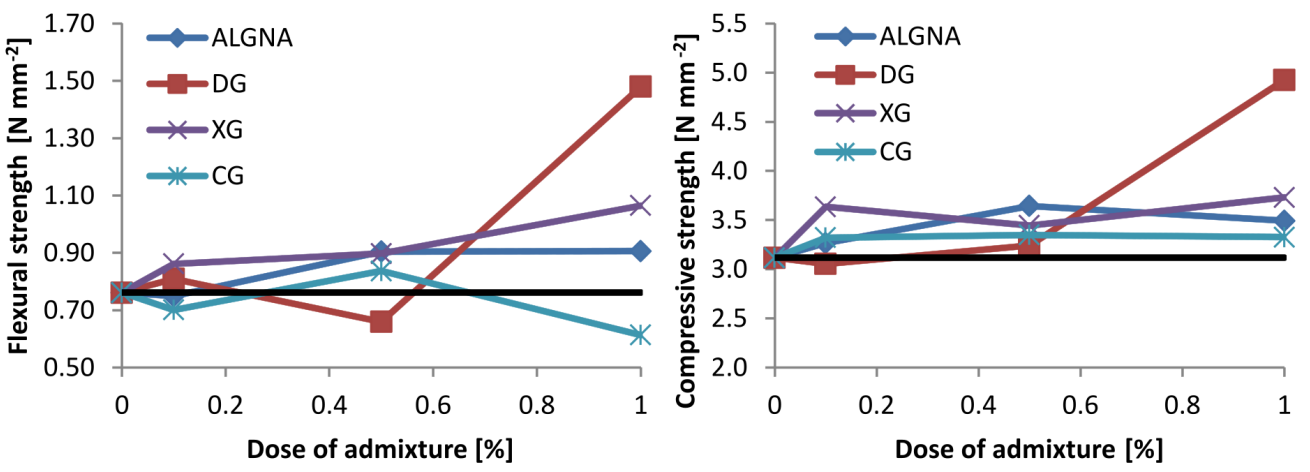

Figure 2. Flexural and compressive strength of mortar specimens 7 days old.
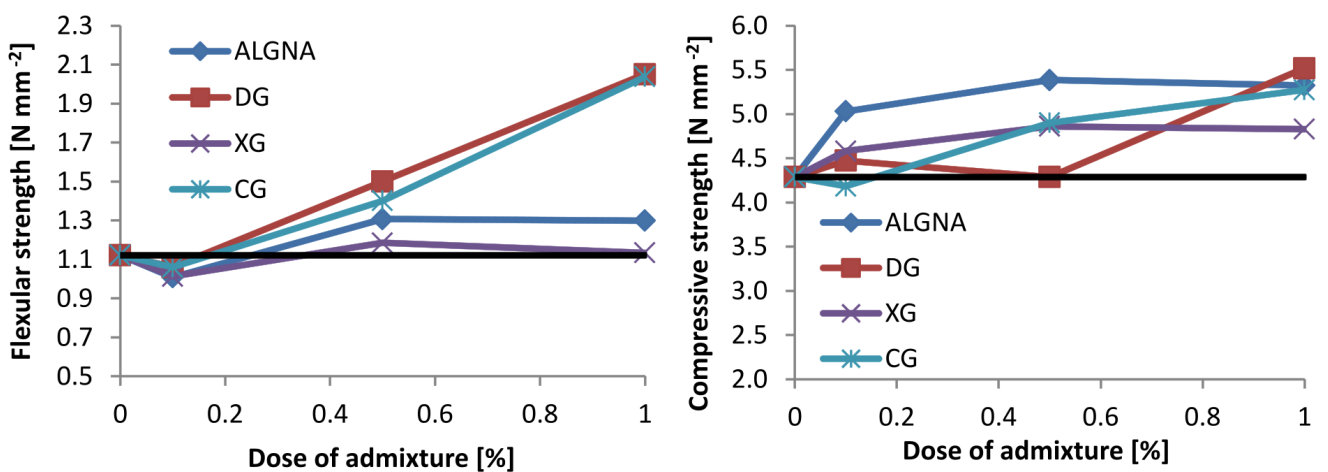

FiguRE 3. Flexural and compressive strength of mortar specimens 28 days old.

\begin{tabular}{|c|c|c|c|c|c|c|c|c|c|c|c|c|c|}
\hline & $\begin{array}{l}\text { 兵 } \\
\text { 王 }\end{array}$ & 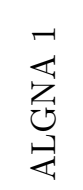 & 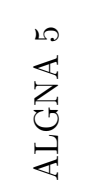 & 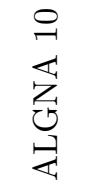 & تૅ & 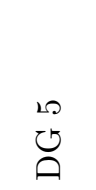 & $\begin{array}{l}\stackrel{0}{1} \\
\underset{\emptyset}{0}\end{array}$ & $\underset{x}{ت}$ & \begin{tabular}{l}
20 \\
$\vdots$ \\
\hdashline
\end{tabular} & $\begin{array}{l}0 \\
\underset{x}{x} \\
\underset{x}{1}\end{array}$ & نَ & $\begin{array}{l}20 \\
0 \\
0\end{array}$ & $\begin{array}{l}\circlearrowright \\
\mho \\
\mho\end{array}$ \\
\hline $\begin{array}{l}\text { Durability } \\
\text { coefficient [-] }\end{array}$ & 0.19 & 0.69 & 1.02 & 0.95 & 0.09 & 0.20 & 0.58 & 0.30 & 0.84 & 0.97 & 0.42 & 0.46 & 0.82 \\
\hline
\end{tabular}

TABLE 1. Durability coefficient of tested mortars. 


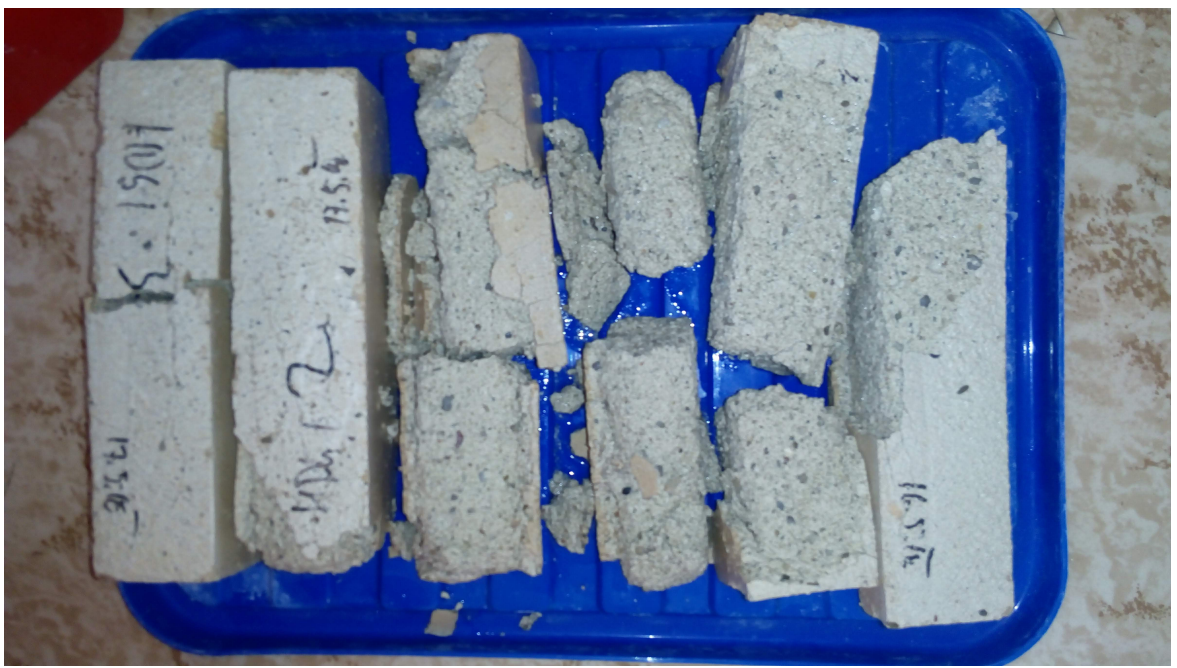

FiguRE 4. DG 1 and DG 5 (three of each from left to right) specimens after durability test.

the specimens with the coefficient of 0.75 and higher are considered to be frost-resistant for the tested count of cycles, thus the ALGNA 5 and 10, XG 5 and 10 and CG 10 specimens are frost resistant for 15 freezingthawing cycles. The values of durability coefficient of ALGNA in the higher doses varied around 1, which indicates extreme durability in comparison with reference mortar, the coefficient higher than 1 can be explained as in the range of measurement errors.

\section{Conclusions}

The hardened physical-mechanical properties and durability of natural hydraulic lime mortars prepared from NHL 3.5 lime with addition of four different biopolymeric admixtures were studied with the following conclusions:

- All the admixtures cause dosage-dependent flow value reduction; the most efficient ones are diutan gum and carrageenan while xanthan gum shows the highest dosage-dependency.

- The addition of biopolymers increases the 7 and 28 days strength. Diutan gum and carrageenan notably increase the 28 days flexural strength, while compressive one sustained similar to other two admixtures.

- Diutan gum addition worsens the durability of mortars, all other admixtures improve durability with dependency on growing dosage, the best performing is sodium salt of alginic acid, showing almost no strength reduction in higher doses.

\section{ACKNOWLEDGEMENTS}

The work has been financially supported by the BUT specific research project FAST-J-18-5274.

\section{REFERENCES}

[1] E. Knapen, D. Van Gemert. Cement hydration and microstructure formation in the presence of water-soluble polymers. Cement and Concrete Research 39:6-13, 2009. DOI:10.1016/j.cemconres.2008.10.003

[2] K. H. Khayat. Viscosity-enhancing admixtures for cement-based materials - An overview. Cement and Concrete Composites 20(2):171-188, 1998. DOI:10.1016/S0958-9465(98)80006-1

[3] Y. V. Ustinova, T. P. Nikiforova. Cement compositions with the chitosan additive. Procedia Engineering 153:810-815, 2016. DOI:10.1016/j.proeng.2016.08.247

[4] J. Plank. Applications of biopolymers and other biotechnological products in building materials. Applied Microbiology and Biotechnology 66(1):1-9, 2004. DOI:10.1007/s00253-004-1714-3

[5] N. Singh, P. C. Mishra, V. K. Singh, K. Narang. Effects of hydroxyethyl cellulose and oxalic acid on the properties of cement. Cement and Concrete Research 33:13191329, 2003. DOI:10.1016/S0008-8846(03)00060-7

[6] M. Rinaudo. Main properties and current applications of some polysaccharides as biomaterials. Polymer International 57:397 - 430, 2008. DOI:10.1002/pi.2378

[7] I. E. Isik, M. Hulusi Ozkul. Utilization of polysaccharides as viscosity modifying agent in self-compacting concrete. Construction and Building Materials 72:239-247, 2014. DOI:10.1016/j.conbuildmat.2014.09.017.

[8] U. T. Bezerra. Biopolymers and Biotech Admixtures for Eco-Efficient Construction Materials. Woodhead Publishing, Duxford, 2016.

[9] F. Van Der Vurst, S. Grunewald, D. Feys, et al. Effect of the mix design on the robustness of fresh self-compacting concrete. Cement and Concrete Composites 82:190-201, 2017. DOI:10.1016/j.cemconcomp.2017.06.005

[10] C. Roca, V. Alves, F. Freitas, M. Reis. Exopolysaccharides enriched in rare sugars: Bacterial sources, production, and applications. Frontiers in microbiology 6:288, 2015. DOI:10.3389/fmicb.2015.00288

[11] L. Xu, H. Gong, M. Dong, Y. Li. Rheological properties and thickening mechanism of aqueous diutan gum solution: Effects of temperature and salts. Carbohydrate polymers 132:620-9, 2015. DOI:10.1016/j.carbpol.2015.06.083 
[12] A. Vazquez, T. Pique. Biopolymers and BiotecH Admixtures for Eco-Efficient Construction Materials. Woodhead Publishing, Duxford, 2016.

[13] T. Žižlavský, M. Vyšvařil, P. Rovnaníková. Characterization of aerial lime-based mortars with addition of biopolymers. IOP Conference Series: Materials Science and Engineering 379:012006, 2018. DOI:10.1088/1757-899X/379/1/012006

[14] A. Mignon, D. Snoeck, K. d'Halluin, et al. Alginate biopolymers: Counteracting the impact of superabsorbent polymers on mortar strength. Construction and Building Materials 110:169-174, 2016. DOI:10.1016/j.conbuildmat.2016.02.033.

[15] Z. Li, L. Zhang. Biopolymers and Biotech Admixtures for Eco-Efficient Construction Materials. Woodhead Publishing, Duxford, 2016.

[16] Z. Abdollahnejad, M. Kheradmand, F. Pacheco-Torgal. Short-term compressive strength of fly ash and waste glass alkali-activated cement based binder (AACB) mortars with two biopolymers. Journal of Materials in Civil Engineering 29(07):04017045, 2017. DOI:10.1061/(ASCE)MT.1943-5533.0001920.

[17] T. Žižlavský, M. Vyšvařil, P. Bayer, P. Rovnaníková. Influence of guar gum derivatives on hardened properties of aerial lime-based mortars. In Special Concrete and Composites 2017, vol. 760 of Key Engineering Materials, pp. 22-29. Trans Tech Publications, 2018. DOI:10.4028/www.scientific.net/KEM.760.22
[18] T. Žižlavský, M. Vyšvařil, P. Bayer, P. Rovnaníková. Properties of aerial lime-based mortars with chitosan ethers. Solid State Phenomena 276:75-82, 2018. DOI:10.4028/www.scientific.net/SSP.276.75

[19] Y. Zhang, Q. Zhao, C. Liu, M. Zhou. Properties comparison of mortars with welan gum or cellulose ether. Construction and Building Materials 102:648-653, 2016. DOI:10.1016/j.conbuildmat.2015.10.116.

[20] R. Ravi, M. Rajesh, S. Thirumalini. Mechanical and physical properties of natural additive dispersed lime. Journal of Building Engineering 15:70-77, 2018. DOI:10.1016/j.jobe.2017.10.009

[21] A. El-Turki, R. Ball, M. A. Carter, et al. Effect of dewatering on the strength of lime and cement mortars. Journal of the American Ceramic Society 93(7):2074 2081, 2010. DOI:10.1111/j.1551-2916.2010.03667.x.

[22] K. Khayat. Frost durability of concrete containing viscosity-modifying admixtures. ACI Materials Journal 92(6):625-633, 1995.

[23] A. Izaguirre, J. Lanas, J. Alvarez. Characterization of aerial lime-based mortars modified by the addition of two different water-retaining agents. Cement and Concrete Composites 33:309-318, 2011. DOI:10.1016/j.cemconcomp.2010.09.008 